\title{
Development and Validation of a Stability-Indicating RP-HPLC Method for Analysis of Racecadotril in Pharmaceutical Dosage Forms
}

\author{
M. MATHRUSRI ANNAPURNA ${ }^{1 *}$, A. NARENDRA ${ }^{2}$ and ALOK SAHU ${ }^{3}$ \\ ${ }^{1}$ Department of Pharmaceutical Analysis \& Quality Assurance, \\ GITAM Institute of Pharmacy, GITAM University, Visakhapatnam, India \\ ${ }^{2}$ Micro Advanced Research Centre, MicroLabs Ltd., Bangalore, India \\ ${ }^{3}$ Roland Institute of Pharmaceutical Sciences, Berhampur, Orissa, India \\ mathrusri2000@yahoo.com
}

Received 31 January 2014 / Accepted 20 February 2014

\begin{abstract}
A simple stability-indicating RP-HPLC method has been developed and validated for the determination of Racecadotril (RAC) in pharmaceutical dosage forms. The mobile phase consisting of methanol and tetra butyl ammonium hydrogen sulphate (80: 20, v/v) was used using isocratic elution with UV detection at $230 \mathrm{~nm}$. The method showed good linearity for RAC in the $5-120 \mu \mathrm{g} / \mathrm{mL}$ range being the square of the correlation coefficient greater than 0.999 . The limit of quantitation (LOQ) and limit of detection (LOD) were found to be 0.87527 and $0.28884 \mu \mathrm{g} / \mathrm{mL}$ respectively. The robustness was also evaluated by variations of mobile phase composition, flow rate and detection wavelength. The forced degradation kinetic study of Racecadotril by using $\mathrm{HCl}$ $(0.1 \mathrm{M}), \mathrm{NaOH}(0.01 \mathrm{M}), \mathrm{H}_{2} \mathrm{O}_{2}(3 \% \mathrm{v} / \mathrm{v})$, thermal $\left(80 \pm 2{ }^{\circ} \mathrm{C}\right)$, hydrolysis and $\mathrm{UV}$ radiation $(365 \mathrm{~nm})$ were observed to be very specific. Finally the applicability of the method was evaluated in commercial dosage form analysis as well as in stability studies.
\end{abstract}

Keywords: Racecadotril, Stability indicating, RP-HPLC, ICH

\section{Introduction}

Racecadotril (RAC), benzyl $N$-[3-(acetylthio)-2 benzylpropanoyl] glycinate (RAC) (Figure 1) also known as acetorphan, is an antidiarrheal drug ${ }^{1}$ which acts as a peripherally acting enkephalinase inhibitor. Unlike other medications it is used to treat diarrhoea, which reduce intestinal motility and has an anti-secretory effect. It reduces the secretion of water and electrolytes into the intestine. Thiorphan is the active metabolite of Racecadotril. A thorough literature survey has revealed that a limited number of chromatographic ${ }^{2-6}$ and spectrophotometric methods ${ }^{7}$ have been reported for the determination of Racecadotril. An exhaustive study on the stability of RAC is demanding as the current ICH guidelines ${ }^{8}$ require that stability analysis should be done by using stability-indicating assay methods, developed and validated after stress testing on the drug under a variety of conditions, including acidic 
degradation, thermal degradation, oxidation, hydrolysis and photolysis. In the present work a selective, precise and accurate RP-HPLC method for the determination of RAC was developed. The validation of the proposed method was also carried out and its applicability was evaluated in commercial dosage form analysis.

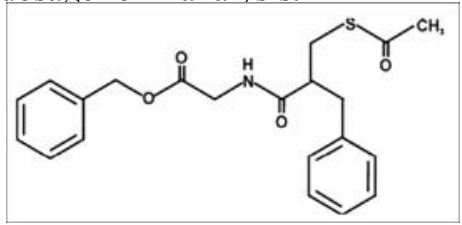

Figure 1. Structure of Racecodotril

The reported methods in the literature suffer from one or the other disadvantage such as poor sensitivity, very narrow linearity range, scrupulous control of experimental variables and the present study reports the development and validation of stability indicating HPLC method with better detection ranges of RAC in pure form and its capsule dosage forms.

\section{Experimental}

Methanol (HPLC grade), Tetra Butyl Ammonium Hydrogen Sulphate (TBAHS) and hydrogen peroxide $(30 \% \mathrm{w} / \mathrm{w})$ solution were purchased from Merck (India) and other chemicals and solvents used were of analytical grade. Water (HPLC grade) was obtained from Milli-Q RO system. Racotil ${ }^{\circledR}$, Cadotril ${ }^{\circledR}$ and Raceloc ${ }^{\circledR}$ capsules, Racecadotril theoretical dose: $100 \mathrm{mg}$ of RAC and Racecadotril reference and working standard RACs were obtained as gift samples from Cipla Laboratories (Mumbai, India).

\section{Instrumentation and chromatographic conditions}

The chromatographic system consisted of a pump, Model LC-Class-Vp version 6.12 SPI Shimadzu, equipped with UV-VIS detector Model SPD-10A, Shimadzu, integrator Model Hypersil ODS C-18 $(25 \times 0.4 \mathrm{~cm}$, packed with $5 \mu)$ column Shimadzu. Injections were carried out using a $20 \mu \mathrm{L}$ loop at room temperature.

The mobile phase was Methanol-TBAHS $(80: 20, \mathrm{v} / \mathrm{v})$ at a flow rate of $1.0 \mathrm{~mL} / \mathrm{min}$. The eluate was monitored at $230 \mathrm{~nm}$. A Shimadzu UV/VIS spectrophotometer 1800 with $1 \mathrm{~cm}$ matched quartz cells was employed for all the spectral measurements.

\section{Preparation of tetra butyl ammonium hydrogen sulphate (TBAHS) solution}

To prepare $(10 \mathrm{mM})$ tetra butyl ammonium hydrogen sulphate (TBAHS) solution about $3.3954 \mathrm{~g}$ was accurately weighed and transferred into a $1000 \mathrm{~mL}$ volumetric flask and dissolved in HPLC grade water. The solution was sonicated, filtered and used for the mobile phase. The solution has $\mathrm{pH}$ of 3.4 .

\section{Preparation of racecadotril solution}

About $50 \mathrm{mg}$ of Racecadotril reference standard was exactly weighed and dissolved in a $50 \mathrm{~mL}$ volumetric flask with mobile phase containing methanol and tetra butyl ammonium hydrogen sulphate $(20: 80, \mathrm{v} / \mathrm{v})$.

\section{Assay of marketed samples}

The contents of 20 capsules of the available marketed formulations were procured from the local pharmacy store (Racotil ${ }^{\circledR}$ and Raceloc $($ ) and powder equivalent to $100 \mathrm{mg}$ was accurately weighed and transferred to a $100 \mathrm{~mL}$ volumetric flask and diluted with mobile phase. The resultant mixture was sonicated for $30 \mathrm{~min}$ and filtered through membrane filter. 


\section{Method validation}

\section{Linearity}

Linearity of the method was evaluated at five different concentration levels by diluting the standard RAC solutions to give solutions over the range $5-120 \mu \mathrm{g} / \mathrm{mL}$ for Racecadotril. These were injected in triplicate and the peak areas were inputted into a Microsoft Excel ${ }^{\circledR}$ spreadsheet program to plot calibration curves.

\section{Precision}

Precision was evaluated in terms of intra-day repeatability and inter-day reproducibility. The intra-day repeatability was investigated using three separate sample solutions each at three different levels $(10,20$ and $50 \mu \mathrm{g} / \mathrm{mL})$ prepared as reported above, from the freshly reconstructed capsule formulations. Each solution was injected in triplicate and the peak areas obtained were used to calculate means and RSD\% values. The inter-day reproducibility was checked on four different days, by preparing and analyzing in triplicate four separate sample solutions from the reconstructed formulations at the same concentration level of intra-day repeatability; the means and $\mathrm{RSD} \%$ values were calculated from peak areas.

\section{Accuracy}

To assess accuracy, freshly prepared placebo of the RAC pharmaceutical formulations were spiked with various amounts of pure RAC at 80, 100 and 120\%. Each solution was injected in triplicate and the peak areas were used to calculate means and $\mathrm{RSD} \%$ values and compared with those obtained with standard RAC solutions.

\section{Robustness}

To determine the robustness three parameters were varied: flow rate, percent composition of eluants and detection wave length. The influence of the $\mathrm{pH}$ of the mobile phase was studied by analyzing the standard RAC mixture at six different values: 3.0, 3.2, 3.4, 3.6 and 3.8. The effect of flow rate was varied by $\pm 0.2 \mathrm{~mL} / \mathrm{min}$ for analyzing RAC. The influence of mobile phase composition was determined by varying the percentages of eluant $\mathrm{A}(78-80-82 \%)$ and eluant B (22-20-18\%).

\section{Forced degradation studies}

Conditions of forced degradation studies were in compliance with recommendations of the International Commission of Harmonization ${ }^{9}$. All degradation studies were performed by exposing the Racecadotril solution to different stress conditions followed by dilution as per the requirement $(20 \mu \mathrm{g} / \mathrm{mL})$. For acidic decomposition study RAC was exposed to $0.1 \mathrm{M}$ $\mathrm{HCl}$ in thermostat maintained at $80 \pm 2{ }^{\circ} \mathrm{C}$ for $1 \mathrm{~h}$, cooled and then neutralized. Similarly the alkaline degradation was performed with $0.01 \mathrm{M} \mathrm{NaOH}$ and then neutralized after cooling. For oxidative stress, $3 \%$ hydrogen peroxide solution was used and for thermal degradation the drug solution was exposed to thermostat maintained at $80 \pm 2{ }^{\circ} \mathrm{C}$ for $1 \mathrm{~h}$. For hydrolysis, RAC was treated with water and placed in the thermostat maintained at $80 \pm 2{ }^{\circ} \mathrm{C}$ for $1 \mathrm{~h}$. Photo degradation studies were carried out at room temperature by exposing solution of RAC $(20 \mu \mathrm{g} / \mathrm{mL})$ to UV-light $(365 \mathrm{~nm})$ for $2 \mathrm{~h}$.

\section{Results and Discussion}

A reversed-phase liquid chromatographic technique was developed to quantitate Racecadotril in pharmaceutical dosage forms. No stability indicating liquid chromatographic method was reported earlier. A detailed comparative study of the previously published methods with the present method was discussed in Table 1. 
Table 1. Comparison of the performance characteristics of the present method with the published liquid chromatographic methods

\begin{tabular}{|c|c|c|c|c|}
\hline Method / Reagent & $\begin{array}{c}\lambda \\
\mathrm{nm}\end{array}$ & $\begin{array}{l}\text { Linearity } \\
\mu \mathrm{g} / \mathrm{mL}\end{array}$ & Remarks & Ref. \\
\hline $\begin{array}{l}\text { Acetonitrile : phosphate } \\
\text { buffer }(40: 60, \mathrm{v} / \mathrm{v})\end{array}$ & 230 & $5-15$ & $\begin{array}{c}\text { Very narrow range } \\
\text { Retention time of drug is } \\
\text { more }(6.9 \mathrm{~min})\end{array}$ & [2] \\
\hline Methanol: water & 231 & $25-100$ & Limited linearity range & {$[3]$} \\
\hline Acetonitrile : water & 232 & $20-80$ & & \\
\hline $\begin{array}{l}\text { Acetonitrile : phosphate } \\
\quad \text { buffer }(74: 26, v / v)\end{array}$ & 210 & $0.05-4.0$ & $\begin{array}{l}\text { Very narrow range } \\
\text { (in plasma) }\end{array}$ & {$[4]$} \\
\hline $\begin{array}{l}\text { Methanol: water } \\
(60: 40, \mathrm{v} / \mathrm{v})\end{array}$ & 220 & $1-32$ & $\begin{array}{l}\text { Limited linearity range and } \\
\text { PDA detector used }\end{array}$ & [5] \\
\hline $\begin{array}{c}\text { Acetonitrile : methanol: } \\
\text { water: acetic acid } \\
(52: 28: 20: 0.1, \mathrm{v} / \mathrm{v})\end{array}$ & 232 & $2-20$ & $\begin{array}{l}\text { Many reagents for } \\
\text { preparing the mobile phase }\end{array}$ & {$[6]$} \\
\hline $\begin{array}{l}\text { Isopropanol: Ammonia: } \\
\text { n-Hexane }(9: 0.5: 20, \mathrm{v} / \mathrm{v})\end{array}$ & 240 & $4-40$ & $\begin{array}{l}\text { Limited linearity range in } \\
\text { all the three method }\end{array}$ & \\
\hline $\begin{array}{l}\text { (HPTLC) (First derivative } \\
\text { spectrophotometry) }\end{array}$ & & $5-40$ & & \\
\hline $\begin{array}{l}\text { (HPLC) Methanol:TBAHS } \\
(80: 20, \mathrm{v} / \mathrm{v})\end{array}$ & 230 & $5-120$ & $\begin{array}{c}\text { Wide linearity range } \\
\text { Stability indicating method }\end{array}$ & $\begin{array}{c}\text { Present } \\
\text { work }\end{array}$ \\
\hline
\end{tabular}

In the initial trials the following mobile phases were used: acetonitrile and water $(20: 80, \mathrm{v} / \mathrm{v})($ mobile phase 1$)$ and acetonitrile and water $(50: 50, \mathrm{v} / \mathrm{v})($ mobile phase 2$)$ as the mobile phases. Mobile phase 1 has been rejected due to a lack of Racecadotril signal on chromatogram. When samples of Racecadotril were analyzed using LiChrospher ODS column and a mobile phase 2, peaks shape was not good and retention time was more than 12 min and therefore organic modifier concentration was changed from $50 \%$ to $70 \%$, but no improvement was observed. Subsequent attempts were made by lowering the $\mathrm{pH}$ of the mobile phase with various buffers including phosphate buffer but the peak shape was disturbed and therefore finally $10 \mathrm{mM}$ tetra butyl ammonium hydrogen sulphate (TBAHS) ( $\mathrm{pH}$ 3.4) was chosen and marked improvement was observed. Eventually, a mobile phase composed of tetra butyl ammonium hydrogen sulphate: methanol $(20: 80, v / v)$ gave the best results. During these studies injection volume was $20 \mu \mathrm{L}$ and the mobile phase flow rate was constant at $1.0 \mathrm{~mL} / \mathrm{min}$. The analytical wavelength was $230 \mathrm{~nm}$.

\section{Method development}

The data obtained from forced degradation study allowed developing a single HPLC assay for the analysis of RAC, in the presence of its degradation products. The concept of robustness of an analytical procedure has been defined by the ICH as a measure of its capacity to remain unaffected by small but deliberate variations in method parameters. The robustness of a method is the ability to remain unaffected by small changes in parameters such as $\mathrm{pH}$ of the mobile phase, temperature, \% organic solvent strength and buffer concentration etc. to determine the robustness of the method experimental conditions were purposely altered and chromatographic characters were evaluated. 


\section{Method validation}

The developed method was validated as described below, for the following parameters: system suitability, specificity, linearity, precision, accuracy and LOD/LOQ. The limit of quantitation was determined as $0.875 \mu \mathrm{g} / \mathrm{mL}$ and limit of detection as $0.288 \mu \mathrm{g} / \mathrm{mL}$.

\section{System suitability}

As system suitability test is an integral part of chromatographic methods development and it is used to verify that the system is adequate for the analysis to be performed, the parameter for Racecadotril was evaluated. The theoretical plates were found to be $4246(\mathrm{~N}>2000)$ and the resolution was $>1.5$. The tailing factor was found to be 1.05 and the capacity factor ( $\left.\mathrm{k}^{\prime}\right)$ was found to be $>2.0$

\section{Linearity}

The linearity of an analytical procedure is its ability, within a given range, to obtain test results which are directly, or through a mathematical transformation, proportional to the concentration of analyte. Seven concentration levels were considered to study the linearity. Overall, these data demonstrated that the excipients and the degradation products did not interfere with the Racecadotril peak, indicating selectivity of the method.

Racecadotril shows linearity over a concentration range $5-120 \mu \mathrm{g} / \mathrm{mL}$ and a calibration curve was drawn by taking the concentration of the drug solution on the $\mathrm{x}$-axis and the corresponding peak area values on the $y$-axis (Figure 2). The regression equation is found to be $\mathrm{Y}=10885 \mathrm{X}+4500$. The correlation coefficient $\left(\mathrm{r}^{2}=0.999\right)$ closed to unity. The values obtained showed good linearity. The calibration data with their relative standard RAC deviations, \% RSD were shown in Table 2.

Table 2. Linearity of Racecadotril

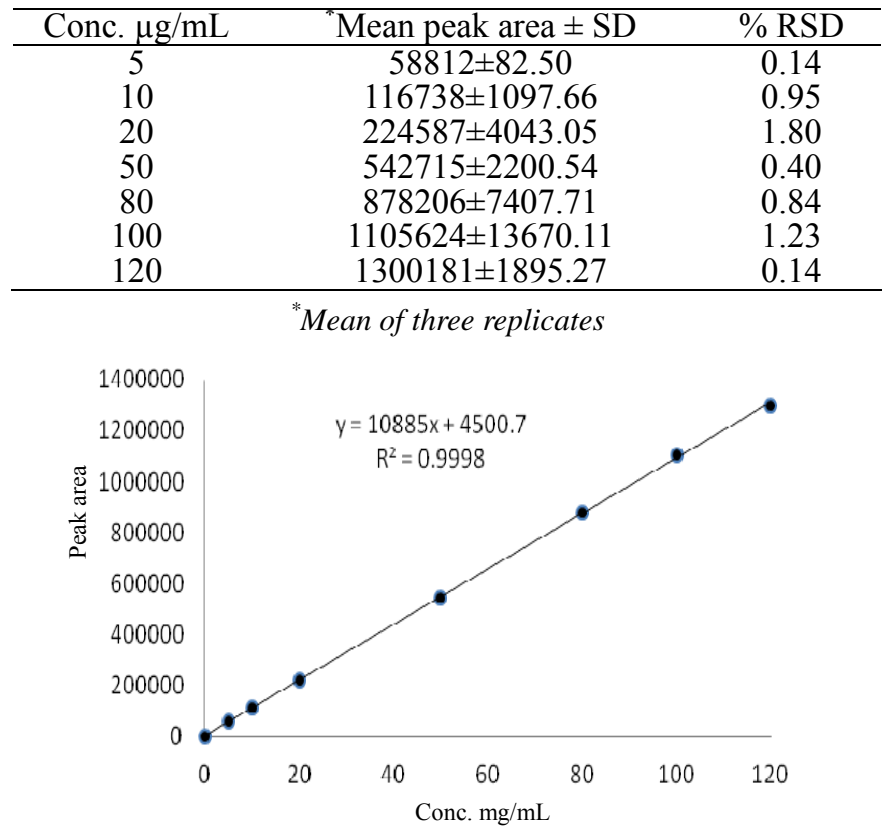

Figure 2. Calibration curve of Racecodotril 


\section{Precision and accuracy}

The $\%$ RSD was found to be less than 2\% in intra-day (0.194-1.003) and inter-day precision (0.62-1.9) studies (Table 3) indicating that the method is more precise. The \% RSD was found to be less than $2 \%$ in intra-day (0.194-1.003) and inter-day precision (0.62-1.9) studies (Table 4) indicating that the method is more accurate. The percentage RSD was found to be $0.893-1.213$ which is less than $2 \%$ indicating that the method is robust.

Table 3. Intra-day and inter-day precision for Racecadotril

\begin{tabular}{|c|c|c|c|c|c|}
\hline \multirow[b]{2}{*}{ Conc. $\mu \mathrm{g} / \mathrm{mL}$} & \multicolumn{2}{|c|}{ Intra-day precision } & \multicolumn{3}{|c|}{ Inter-day precision } \\
\hline & $\begin{array}{l}\text { Mean peak area } \\
\pm \mathrm{SD}(\mathrm{n}=3)\end{array}$ & RSD \% & \multicolumn{2}{|c|}{$\begin{array}{c}\text { Mean peak area } \pm \text { SD } \\
(\mathrm{n}=3)\end{array}$} & RSD \% \\
\hline 10 & $113687 \pm 220.617$ & 0.194 & 1154 & $5.66 \pm 2254.72$ & 1.9 \\
\hline 20 & $221254.3 \pm 2219.51$ & 1.003 & 2277 & $5.33 \pm 1876.09$ & 0.82 \\
\hline 50 & $552344.7 \pm 1671.71$ & 0.302 & 5544 & $.66 \pm 3446.929$ & 0.62 \\
\hline \multicolumn{6}{|c|}{ "Mean of three replicates } \\
\hline $\begin{array}{c}\text { Amount (\%) of } \\
\text { drug added }\end{array}$ & $\begin{array}{c}\text { Theoretical } \\
\text { Content } \mu \mathrm{g} / \mathrm{mL}\end{array}$ & \multicolumn{2}{|c|}{$\begin{array}{l}\text { Conc. Found } \\
\mu \mathrm{g} / \mathrm{mL} \pm \text { S.D }\end{array}$} & $\begin{array}{c}\% \\
\text { Recovery }\end{array}$ & $\begin{array}{c}\text { RSD } \\
\%\end{array}$ \\
\hline 80 & 36 & 35.89 & .125 & 99.71 & 1.24 \\
\hline 100 & 40 & 39.49 & .080 & 98.74 & 0.99 \\
\hline 120 & 44 & 43.51 & .194 & 98.90 & 0.19 \\
\hline
\end{tabular}

\section{Analysis of marketed formulations}

The present method was applied to the analysis of RAC in three different marketed

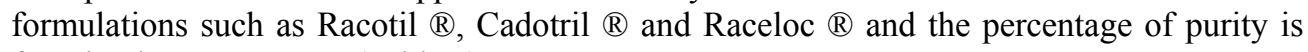
found to be 99.73-99.76 (Table 5).

Table 5. Analysis of marketed formulation (Capsules)

\begin{tabular}{cccc}
\hline Formulation & Labeled amount $\mathrm{mg}$ & Amount found $\mathrm{mg}$ & $\%$ Recovery \\
\hline Brand I & 100 & 99.73 & $99.731 \pm 0.05$ \\
Brand II & 100 & 99.96 & $99.965 \pm 0.03$ \\
Brand III & 100 & 99.85 & $99.854 \pm 0.09$ \\
\hline
\end{tabular}

\section{Forced degradation studies}

The specificity of the method was determined by exposing the drug solution to stress conditions, i.e. $0.1 \mathrm{~N} \mathrm{HCl}, 0.01 \mathrm{~N} \mathrm{NaOH}, 3 \% \mathrm{H}_{2} \mathrm{O}_{2}$, thermal, hydrolysis and $\mathrm{UV}$ light $(365 \mathrm{~nm})$. The resultant chromatograms were interpreted using the chromatogram of Racecodotril (Figure 3). In the forced degradation study all the stress conditions required by ICH guidelines were included; moreover in RAC to avoid unrealistic degradation pathways, the conditions were adjusted to obtain a $10-25 \%$ degradation of the parent compound. Three degradation products were observed at 2.867, 3.65 and $3.925 \mathrm{~min}$ during the acidic degradation (Figure 4A), where as in alkaline degradation, in presence of $0.1 \mathrm{M} \mathrm{NaOH}$ the drug has undergone degradation completely and therefore further the study was done by lowering the alkali concentration by ten times i.e. degradation was studied with $0.01 \mathrm{M}$ $\mathrm{NaOH}$ where and the drug peak was observed with two degradants at 3.642 min and 3.917 min. In oxidative stress, hydrolysis and UV degradation studies racecadotril has undergone less than $20 \%$ degradation. The resultant chromatograms as well as the absorption specta were shown in Figure 4A-4F and Figure 5A- 5E. 


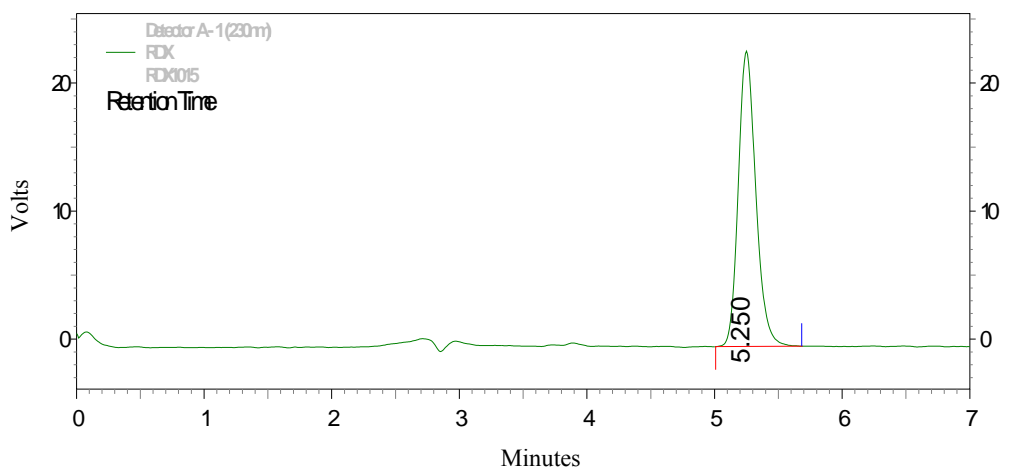

Figure 3. Typical chromatogram of Racecodotril $(20 \mu \mathrm{g} / \mathrm{mL})$

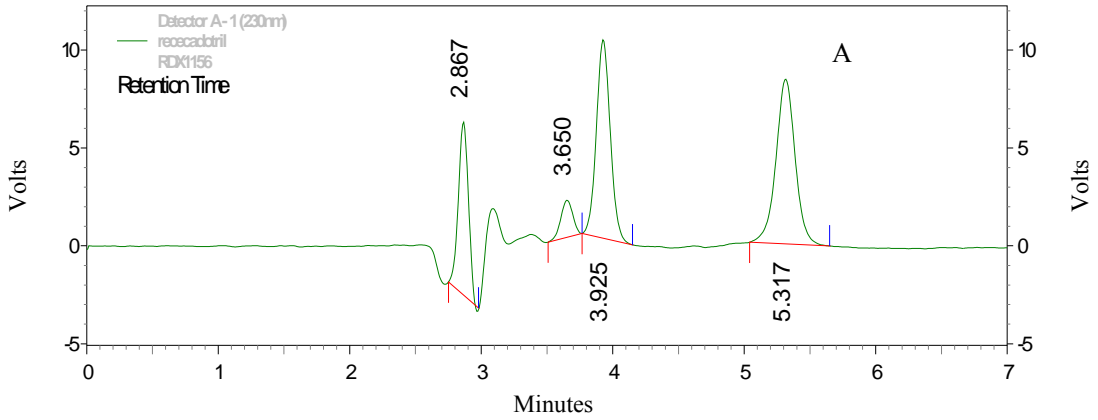

Figure 4A. Typical chromatogram of acidic degradation

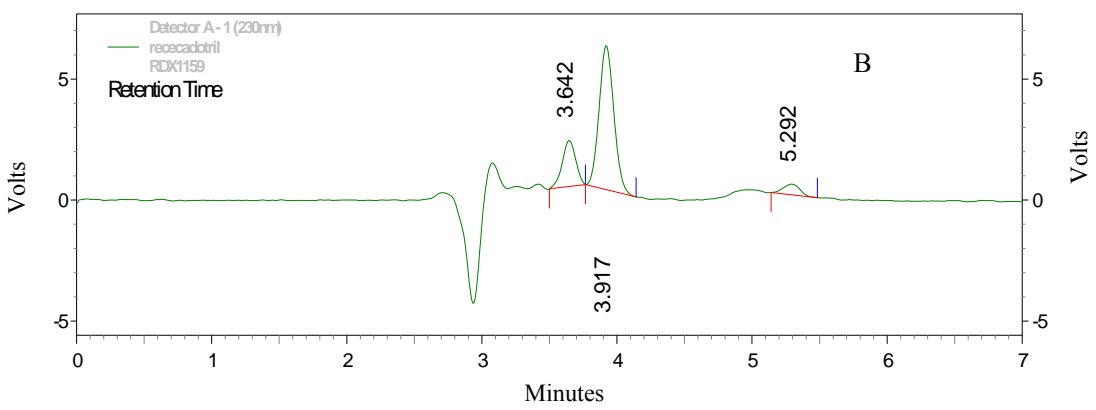

Figure 4B. Typical chromatogram of alkaline degradation

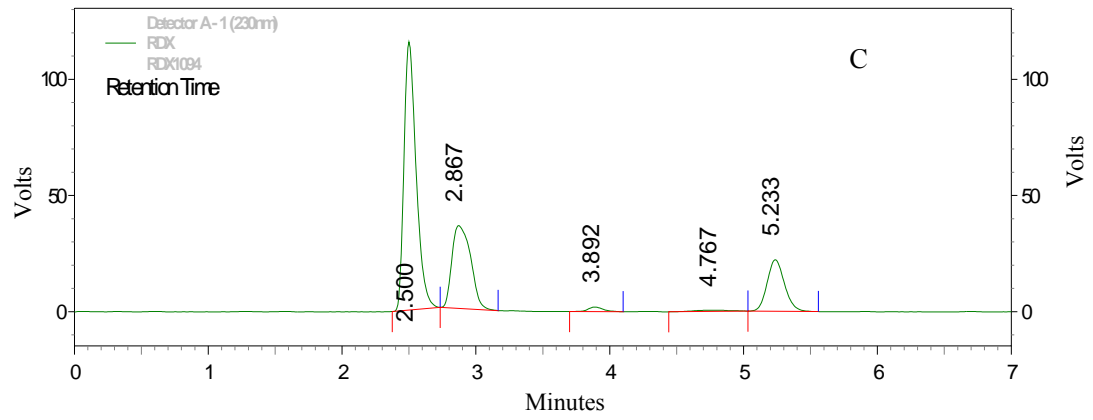

Figure 4C. Typical chromatogram of oxidative degradation 


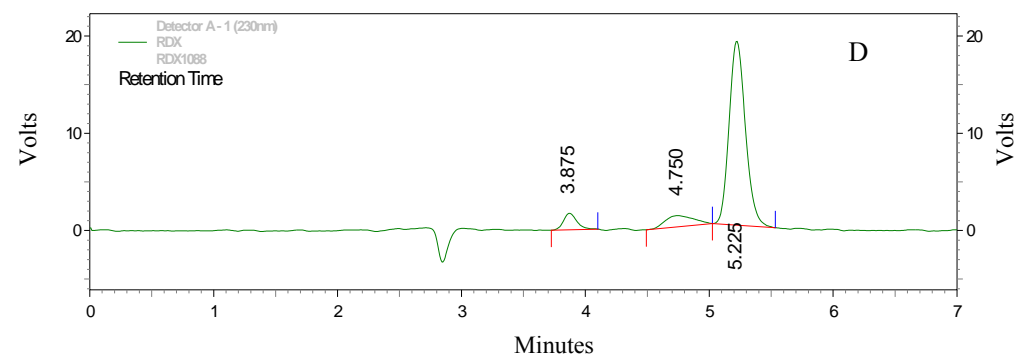

Figure 4D. Typical chromatogram of thermal degradation $\left(80 \pm 2^{\circ} \mathrm{C}\right)$

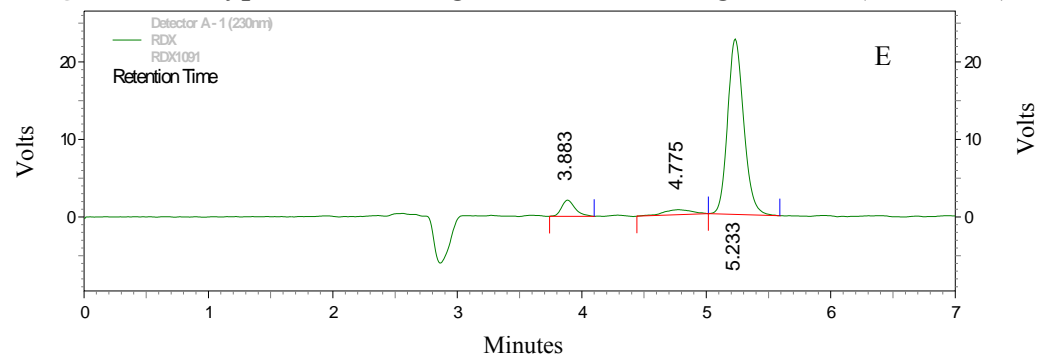

Figure 4E. Typical chromatogram of hydrolytic degradation

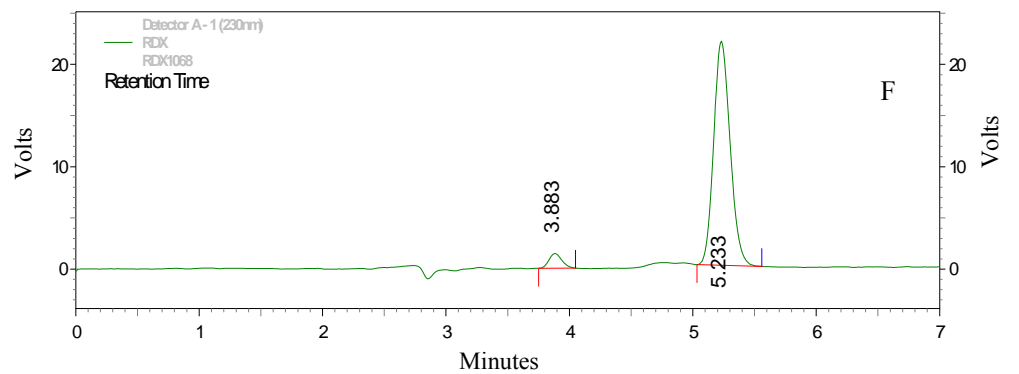

Figure 4F. Typical chromatogram of photolytic degradation

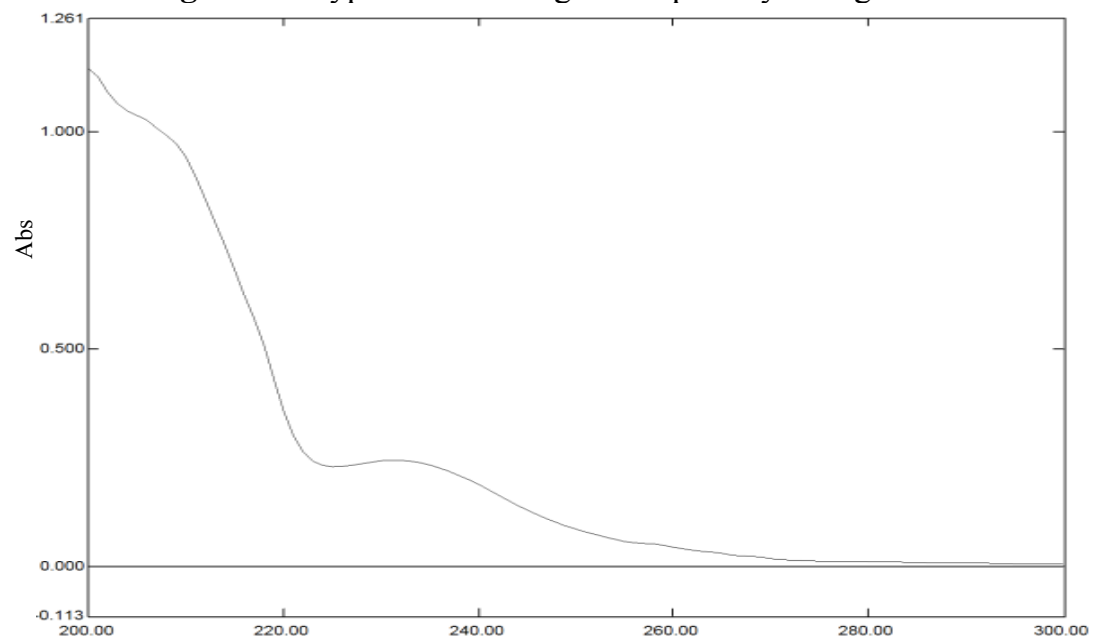

Figure 5A. Absorption spectrum of Racecadotril (Pure) $(20 \mu \mathrm{g} / \mathrm{mL})$ 


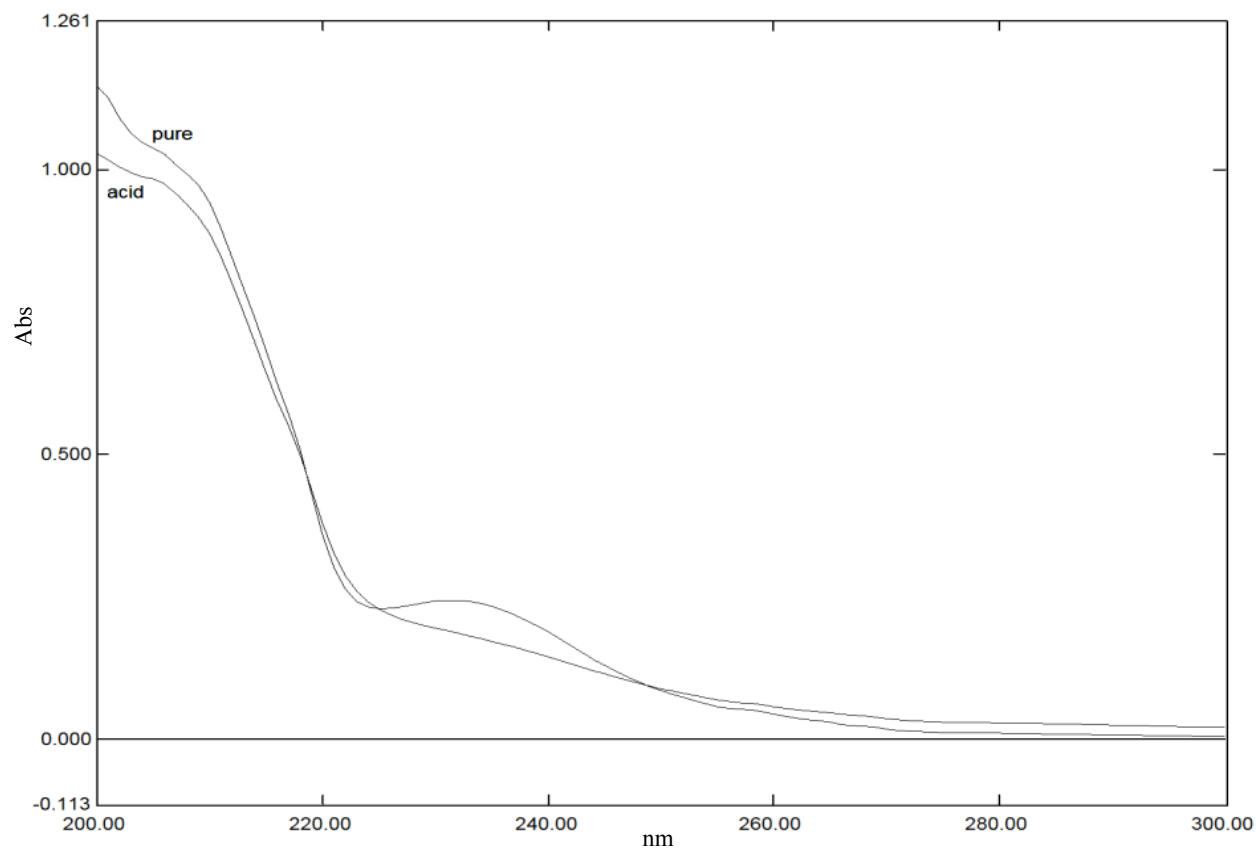

Figure 5B. Resultant absorption spectrum of acidic degradation

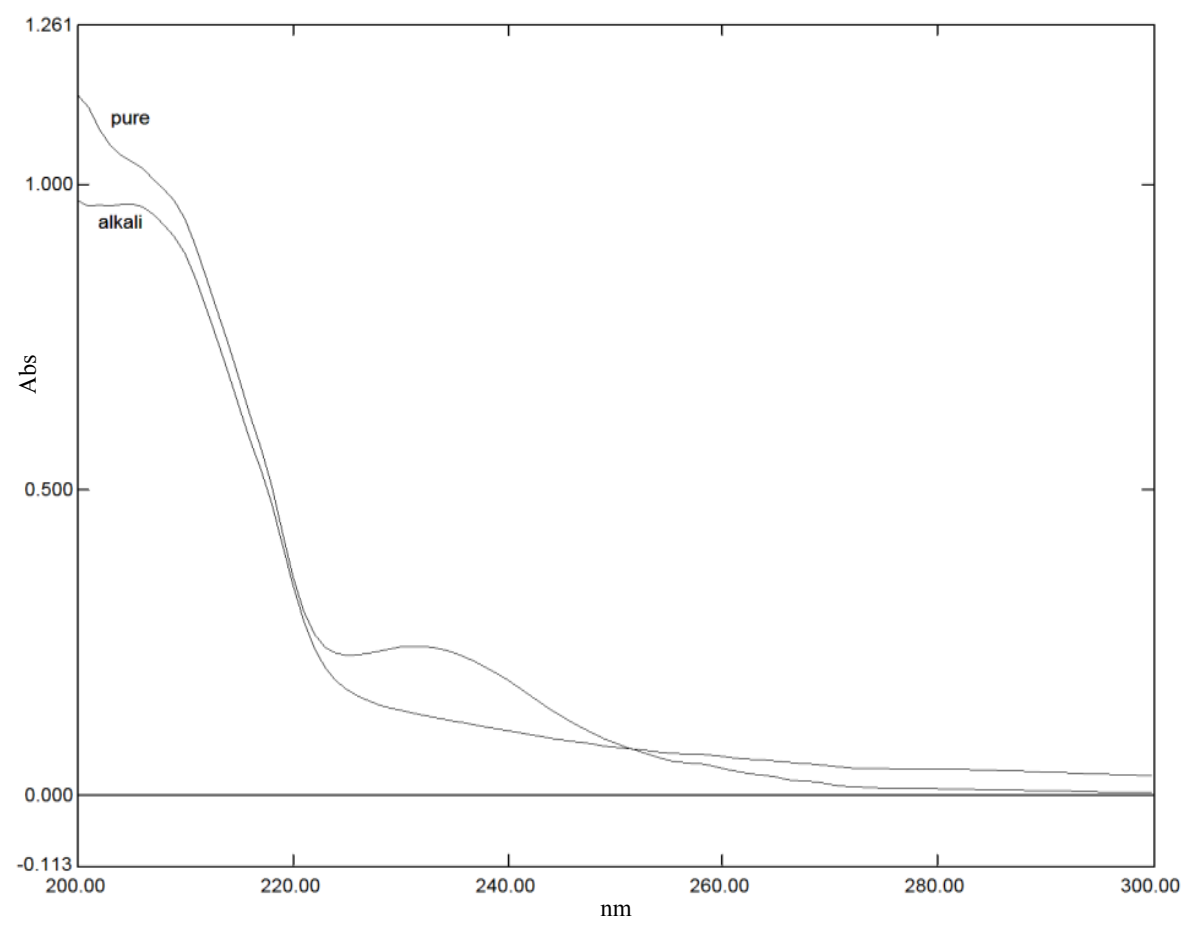

Figure 5C. Resultant absorption spectrum of alkaline degradation 


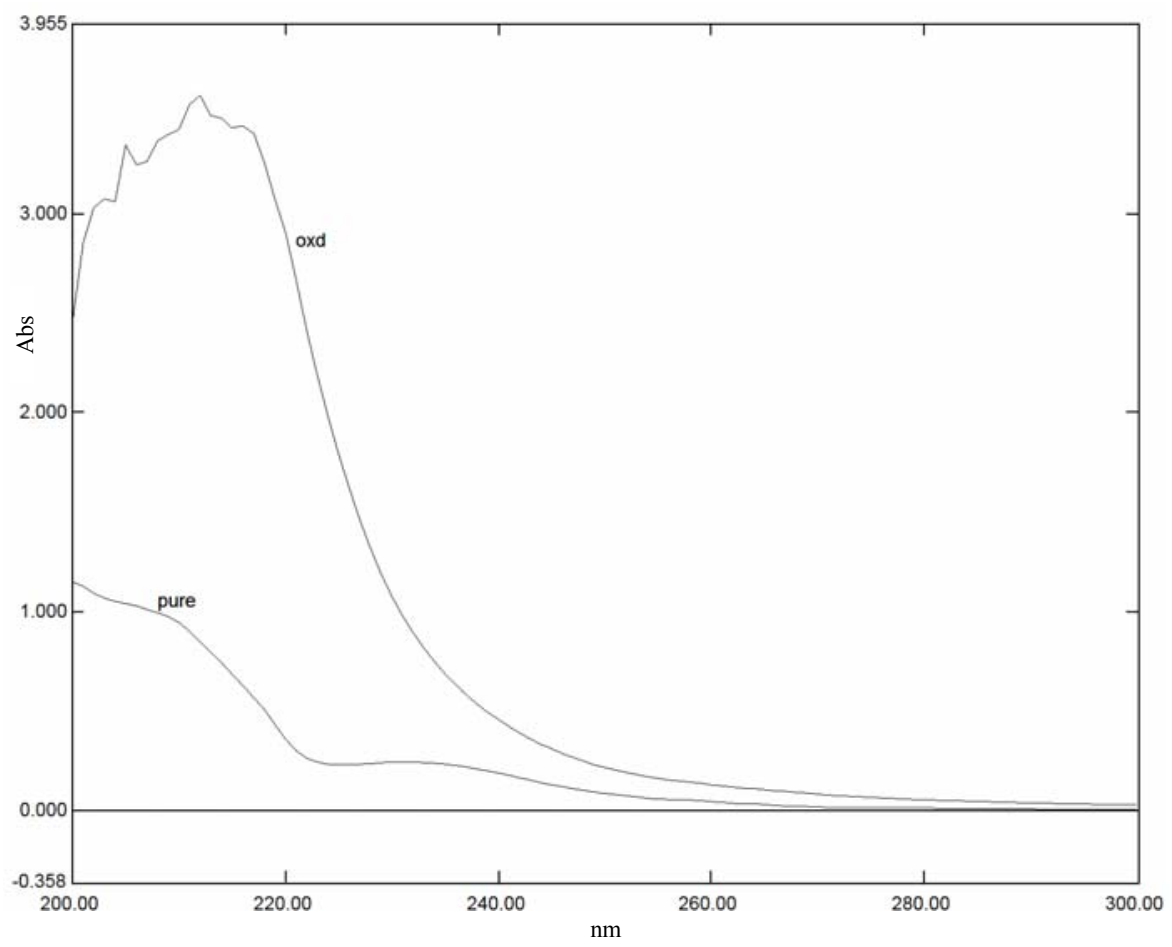

Figure 5D. Resultant absorption spectrum of oxidative degradation

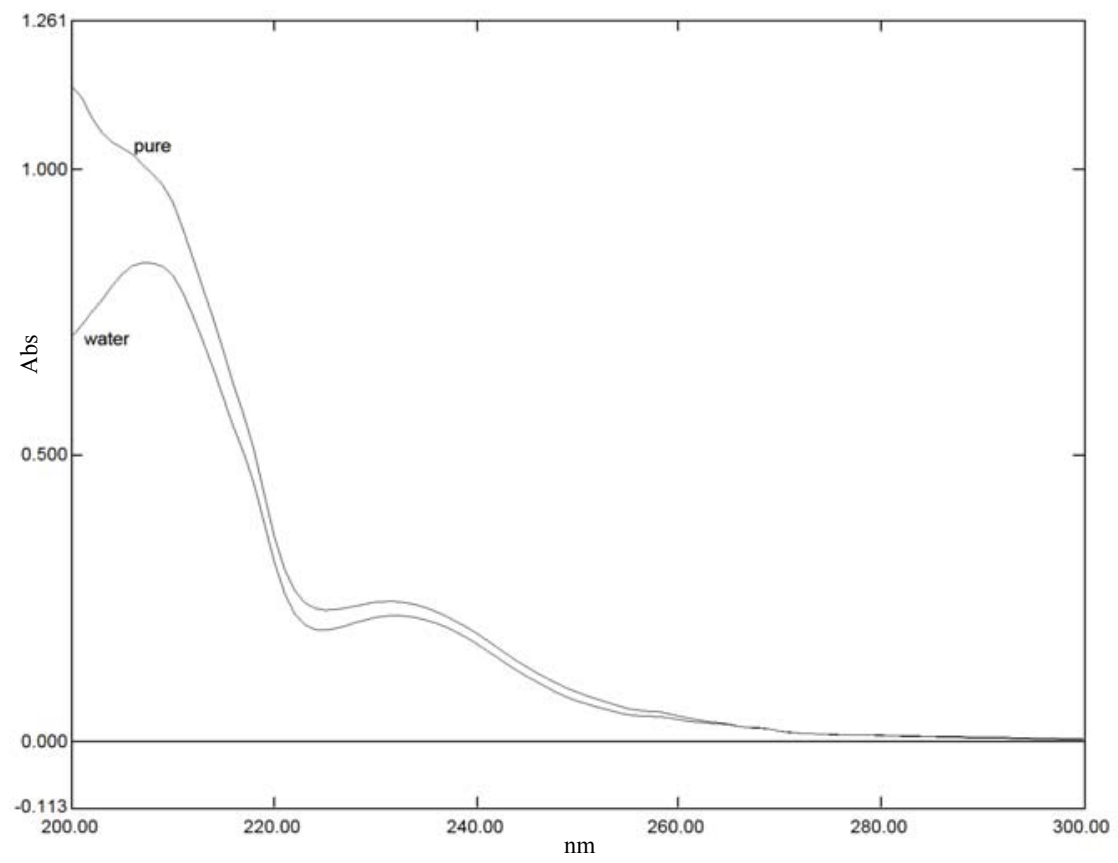

Figure 5E. Resultant absorption spectrum of Hydrolysis 


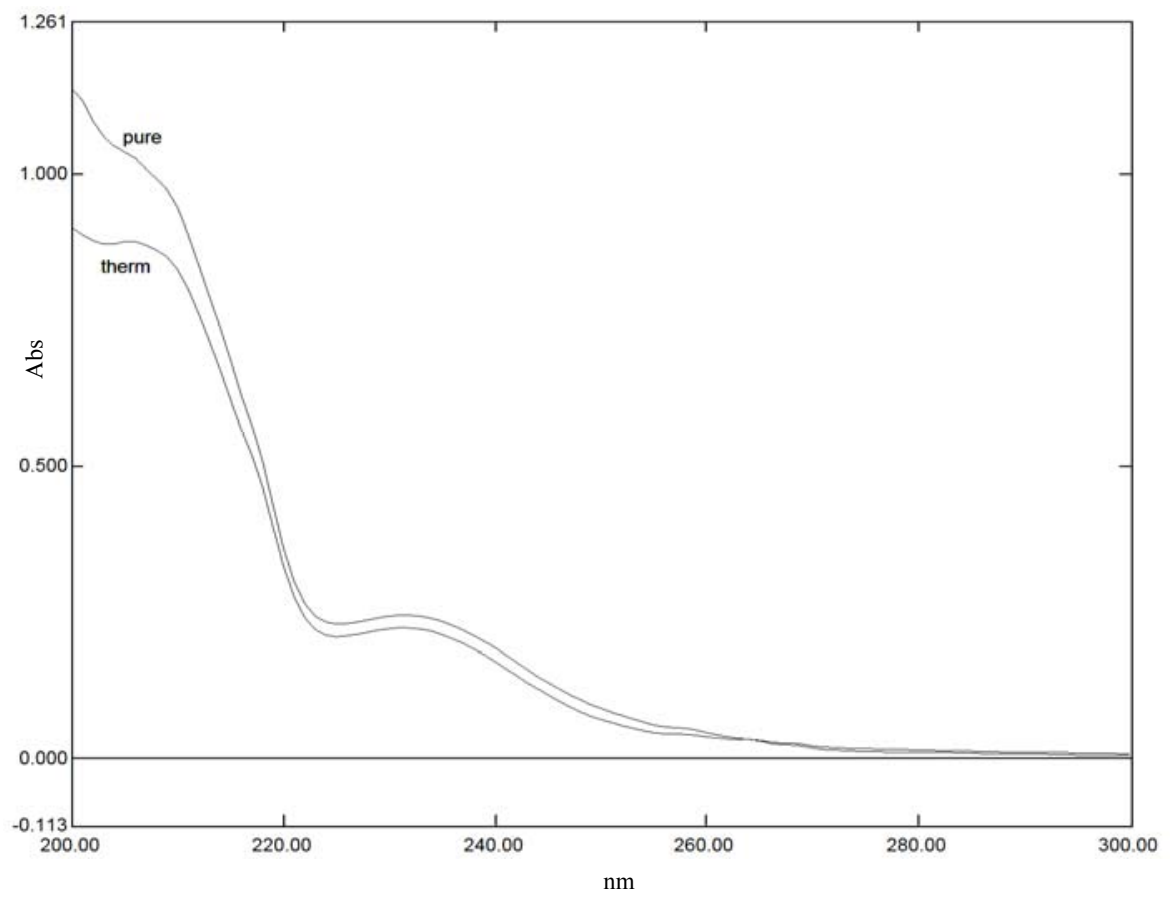

Figure 5F. Resultant absorption spectrum of thermal degradation $\left(80 \pm 2^{\circ} \mathrm{C}\right)$

\section{Conclusion}

The development and validation of a stability-indicating HPLC method for the determination of RAC in presence of degradation products in the active ingredient and its pharmaceutical formulations was sensitive, precise and accurate. The complete separation of the analytes was accomplished in less than 10 min and the method has been successfully used to perform long-term and accelerate stability studies of RAC formulations.

\section{Acknowledgement}

We are grateful to Roland Institute of Pharmaceutical Sciences, Berhampur, Orissa, India for providing the research facilities and Cipla Laboratories, India for providing gift samples of Racecodotril.

\section{References}

1. O’Neil M J, The Merck Index, Fourteen Ed., Merck Research Laboratories, Whitehouse Station, NJ, 2006.

2. Prabu S, Singh T, Joseph A, Kumar C and Shirwaikar A, Ind J Pharm Sci., 2007, 69(6), 819-821; DOI:10.4103/0250-474X.39442

3. Vetrichelvan T and Prabakaran S, Indian J Pharm Sci., 2007, 69(2), 307-309; DOI:10.4103/0250-474X.33168

4. Fan Xua, Lingli Yangb and Guili Xua, J Chromatogr B, 2008, 861(1), 130-135; DOI:10.1016/j.jchromb.2007.11.038

5. Pawan K Basniwal, Prabhat K Srivastava, Surendra K Jain and Deepti Jain, $J$ Chromatogr., 2008. 68, 641-647. 
6. Mohamed A O, Fouad M M, Hasan M M, Abdel Razeq S A and Elsherif Z A, National Center for Biotechnology Information, 2009, 3, 247-252.

7. Lakshmana Rao A, Rajeswari K R and Sankar G G, J Chem Pharm Res., 2010, 2(1), 280-282.

8. Validation of Analytical Procedures: Methodology, Text and Methodology, ICH Harmonised Tripartite Guidelines, 2005.

9. Stability Testing of New Drug Substances and Products, ICH Harmonized Tripartite Guidelines, 1995. 